\title{
Cartografías Discrepantes. La ciudad de La Plata vista y vivida desde la periferia.
}

Ramiro Segura [1]

\section{Resumen}

El presente artículo indaga en los sentidos y las experiencias que de la ciudad tienen los residentes de la periferia urbana de La Plata (Argentina), a partir del análisis de los dibujos de la ciudad realizados por sus residentes. En lugar de analizar los dibujos por el grado de adecuación con respecto a la ciudad, el punto de partida analítico consiste en pensar las diferencias en las representaciones de la ciudad como indicios de experiencias urbanas disímiles. En este artículo nos detenemos específicamente en el "punto de vista periférico": ¿cómo miran, viven y sienten la ciudad quienes habitan un espacio situado fuera de lo que habitualmente se (re) conoce como "la" ciudad?

Palabras clave: ciudad; dibujos; experiencia urbana

\section{Abstract}

This article explores the senses and the experiences of the city's residents have the urban fringe of La Plata (Argentina), from the analysis of drawings made by city residents. Instead of analyzing the drawings of the people by the degree of adequacy for the city, the analytical starting point is to think the differences in the representations of the city evidence of disparate urban experiences.

In this article we stop specifically at the "point of view peripheral": how they look, live and feel the city who inhabit a space outside what is usually (re) known as "the city"?

Key words: city; drawings; urban experience 
"En aquel Imperio, el Arte de la Cartografía logró tal Perfección que el mapa de una sola Provincia ocupaba toda una Ciudad, y el mapa del imperio, toda una Provincia. Con el tiempo, esos Mapas Desmesurados no satisfacieron y los Colegios de Cartógrafos levantaron un Mapa del Imperio, que tenía el tamaño del Imperio y coincidía puntualmente con él. Menos Adictas al Estudio de la Cartografía, las Generaciones Siguientes entendieron que ese dilatado Mapa era Inútil y no sin Impiedad lo entregaron a las Inclemencias del Sol y de los Inviernos. En los desiertos del Oeste perduran despedazadas Ruinas del Mapa, habitadas por Animales y por Mendigos; en todo el País no hay otra reliquia de las Disciplinas Geográficas".

Jorge Luis Borges, Del rigor en la ciencia

\section{Introducción}

Durante una larga entrevista a Carlos, un ex militante sindical y actual referente de un club de jubilados de unos 60 años que vive en una zona periférica de la ciudad, describió a La Plata como "encerrada entre cuatro fierros" y al preguntarle a qué se refería sostuvo "tratan de hacer todo en el centro, fuera de la ciudad, si vos anduviste por acá, ¿qué hay?”. Realizando un evidente esfuerzo por explicarme de varias maneras distintas y complementarias a qué se refería, pidió una hoja y una lapicera a su actual mujer, que nos cebaba mate y asentía silenciosamente a la mayor parte de sus afirmaciones durante la entrevista, realizada 
en una de las habitaciones del club, que hacía las veces también de morada de la pareja, y procedió a realizar el siguiente dibujo:

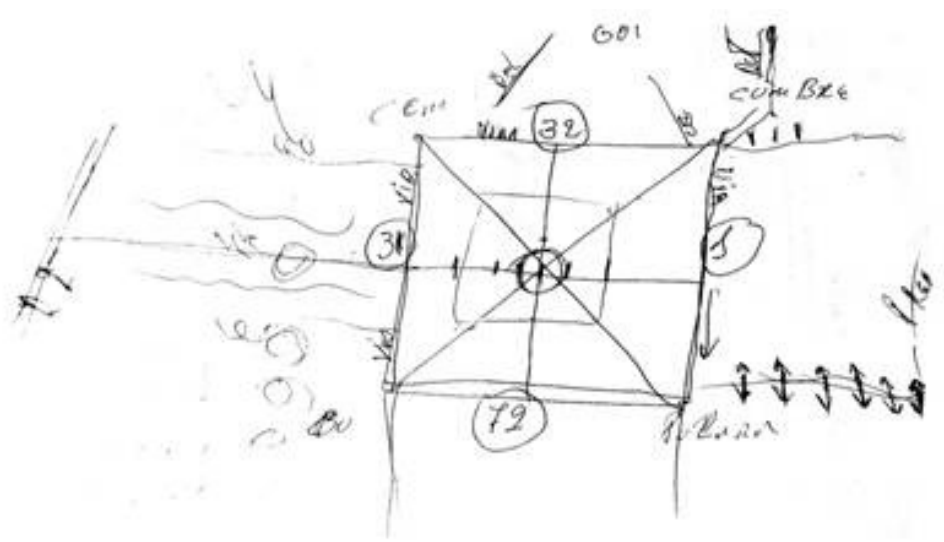

Mientras lo realizaba relataba los pasos dados, especificando cada elemento de su composición: "La ciudad está así: esta es la ciudad [dibuja un cuadrado], esta es la plaza Moreno [la ubica en el centro del cuadrado], las diagonales [dibuja dos líneas que cruzan el cuadrado y se intersectan en el centro, la plaza Moreno], y acá tenés [en cada uno de los vértices del cuadrado] Punta Lara, Cementerio, La Cumbre y El Boulevard. Acá adentro [señala el cuadrado] tenés todo: terminal, facultades, catedral, municipalidad, casa de gobierno, legislatura, el bosque... todo esto corre así [numera los lados del cuadrado] esta es la calle 1, esta es la calle 31 , esta es la 32 y esta es la 72. Todo, todo lo tenemos acá. Todo en este cuadrado. Y todo está rodeado de vías: en la 1 tenemos vías, en la 31 tenemos vías, en la 72 tenemos vías. Todo fierros. Por eso dije que la ciudad de La Plata está en cuatro fierros. Y afuera tenemos Los Hornos, Abasto, Echeverri, 
Romero, la ruta 2. De acá para allá [se refiere a la avenida 32] tenemos Gonnet, City Bell, Villa Elisa, acá viene el Belgrano y acá el Centenario [principales vías de comunicación entre estas localidades] y acá tenemos la que va a Buenos Aires, la autopista. Después acá tenés [más allá de lo que señaló como calle 1] Ensenada, el Dique, Berisso. Después tenés 44, la que va a Echeverri y a la ruta 2. Esto [señala a ambos lados de 44] está prácticamente todo poblado, Los Hornos, Abasto, Echeverri, hay muchos que son todos quinteros. Y entonces -se pregunta con clara indignación- por qué para acá [señala más allá de 72, la zona en la que vive] no hicieron nada, no hay edificios, colegios, hospitales".

Se trata de un dibujo con una visión de conjunto de la ciudad exhaustiva e inusual. A la vez, es una representación visual de la ciudad increíblemente rica en sugerencias, indicios e ideas acerca de las imágenes de la ciudad y de las significaciones y los sentimientos asociados a ellas, como la persistencia de la forma fundacional de la ciudad como límite relevante y marco de localización y lectura de la propia posición y de las diversas localidades e hitos urbanos; de la relación entre el centro ("la ciudad") y la periferia; y de la relevancia de la posición social y espacial de quien dibuja la ciudad en el tipo de dibujo que realiza, las significaciones que le atribuye y los sentimientos asociados al 
mismo; cuestiones todas que analizaremos con más detalle en lo que sigue.

\section{Las imágenes de la ciudad como problema interpretativo}

El trabajo con y sobre dibujos de la ciudad tiene una larga historia en las ciencias sociales que se remonta, al menos, al texto pionero de Kevin Lynch (2006) La imagen de la ciudad, publicado originalmente en 1960. A partir de esos años, diversos investigadores, en mayor medida urbanistas críticos con el funcionalismo y racionalismo modernista dominantes largo tiempo en la arquitectura y luego psicólogos cognitivistas y geógrafos de la percepción del espacio, aunque también algunos semiólogos y antropólogos, se han aventurado en el trabajo con dibujos de la ciudad. El campo es vasto y los debates múltiples. Sin embargo, la pregunta en la cual las distintas investigaciones convergen $-\mathrm{y}$ en torno a la cual discuten- es ¿qué llegamos a conocer a través de estos dibujos? En tanto práctica significante ¿a qué están sustituyendo? Para decirlo de modo más literal: esos trazos realizados sobre un papel blanco, algunos débiles y dubitativos, indecisos, otros firmes y decididos, seguros, ¿de qué nos hablan? ¿Cómo interpretarlos?

Como es habitual, la bibliografía sobre el tema está dividida; incluso la terminología ha ido variando con el correr de los años. Desde la noción de "imagen de la ciudad" de Lynch, que remite 
específicamente a las propiedades de diseño de las ciudades que las tornan, según los casos, más o menos imaginables y representables, legibles, para sus residentes y visitantes, pasando por los trabajos sobre "mapas mentales" de Gould (1966), noción que refiere a plasmar en el mapa las preferencias de un grupo social, hasta llegar al concepto de "mapa cognitivo" de Lowenthal (1967) entendido como una abstracción del modelo que del espacio cada usuario de la ciudad tiene en su cabeza, e incluyendo a cognitivistas más recientes (Castro, 1999) que desechan el uso literal del término "mapa" y cuestionan que para conocer los procesos cognitivos implicados en la orientación espacial de las personas comunes y corrientes en la ciudad sea necesario solicitarles que dibujen un mapa de la misma, se ha abierto un campo de disputa y disenso acerca de la respuesta a la pregunta: estos dibujos ¿de qué hablan?

Sin pretensiones de exhaustividad sobre una producción amplia, existen dos puntos principales de discusión relevantes para nuestros objetivos. Por un lado, una vez que se acepta que los procesos mentales o cognitivos tienen efectivamente alguna importancia en las prácticas espaciales, el debate versa acerca de saber en qué medida los dibujos de la ciudad nos acercan a los procesos cognitivos implicados en la práctica del espacio. En última instancia, los cognitivistas más críticos a la técnica de solicitar dibujos de la ciudad se preguntan si realmente los procesos cognitivos vinculados con las prácticas espaciales tienen 
un lenguaje cartográfico (Castro, 1999). Por otro lado, se discute en qué medida los dibujos que sobre un espacio determinado realiza una persona son expresión de sus prácticas espaciales. Sin bien es de suponer que las propias prácticas de la ciudad tienen algún tipo de importancia en la confección del dibujo, es indudable que otro tipo de informaciones (como mapas $\mathrm{y}$ fotos) $\mathrm{y}$ experiencias -por no incluir las capacidades diferenciales de los sujetos para memorizar un espacio $\mathrm{y}$ traducirlo al lenguaje cartográfico- tienen igualmente importancia en el momento en que un investigador le solicita a su entrevistado que dibuje "su" ciudad. Así, la tríada "procesos mentales o cognitivos - prácticas espaciales - dibujos de la ciudad" forman parte de un largo debate acerca de sus vinculaciones.

Hay un punto, sin embargo, donde la mayoría de estas investigaciones se encuentra. En la mayor parte de los trabajos consultados predomina, generalmente implícita, una "teoría de la adecuación" entre representación y realidad. Es decir, desde esta posición sería posible (y deseable) contrastar el mapa con el territorio (la representación de la ciudad con la ciudad) ponderando en cada caso la distancia o desvío existente entre la representación y el objeto representado, procedimiento por medio del cual se supone podríamos identificar en qué medida aquella se adecua a éste. Llevando tal ejercicio al extremo, el dibujo perfecto de una ciudad sería uno de esos Mapas Desmesurados que se corresponde punto por punto con ella, llegando a la aporía de 
reproducirla. Por supuesto, esa representación sería de dudosa utilidad y merecidamente tendría que ser abandonada a las inclemencias del tiempo y al olvido, como nos narra la ironía borgeana colocada como epígrafe. Los problemas que presenta este tipo de operación analítica se multiplican hasta el infinito. En última instancia ¿cómo contrastar representación con realidad? ¿Qué es la realidad? ¿Y cómo aprehenderla, si no es por medio de representaciones?

De hecho, en la mayor parte de las investigaciones "la ciudad" con la que se contrastan los "dibujos de la ciudad" es un tipo específico de representación que, por la supuesta naturaleza o cualidad mimética que habitualmente atribuimos a las imágenes (precisamente, por la idea de que hay representaciones que reflejan lo real adecuadamente), pasa por no ser tratada como tal, como signo, y en consecuencia, se confunde con la realidad. Se trata de las representaciones cartográficas de la ciudad. De este modo, el contraste que habitualmente se realiza es comparar los dibujos con la cartografía oficial de la ciudad, representación a partir de la cual se identifican desvíos, ausencias, desproporciones y correspondencias, sin explicitar el desplazamiento que efectivamente el analista consuma entre realidad y representación cartográfica, confundiéndolas y arribando a conclusiones equívocas.

Por esto, es necesario destacar ciertas cualidades del "lenguaje cartográfico", mediación fundamental que muchas de las 
investigaciones pierden de vista. De Certeau (2000) ha señalado, por ejemplo, que la condición de existencia de los planos urbanos depende, en general, de la abstracción o el olvido de las prácticas espaciales. Y la cartografía crítica (Harley, 2001) se ha esforzado por distanciarse (y desentrañar los mecanismos) del pensamiento positivista, racionalista y objetivista propios de la geografía, lo que ha posibilitado entender al mapa más como un texto que como una imagen fiel de lo real. Es por esto que en nuestras entrevistas se solicitaban "dibujos de la ciudad" y no "mapas de la ciudad". Que la mayoría de los entrevistados, sin embargo, hayan efectivamente realizado sus dibujos recurriendo al "lenguaje cartográfico", es decir, que hayan construido una imagen de la ciudad sobre un plano bidimensional, aplicando tramas ortogonales, buscando respetar proporciones, posiciones, distancias y relaciones entre los objetos que colocaban en ellas, es un dato significativo sobre el cual trabajaremos en este artículo.

Aquí solo cabe decir al respecto que dicho dato nos lleva a reflexionar (y discutir) sobre dos énfasis generalmente compartidos por quienes trabajan con "mapas mentales" o "mapas cognitivos". Por un lado, el énfasis en colocar el foco en las relaciones entre individuo y ambiente, entendiendo que los mapas son producto (casi) exclusivo de tal relación. Por el otro, el énfasis en priorizar cuestiones perceptivas, generalmente visuales, en la relación individuo-ambiente. Ambos énfasis pierden de vista (o en el mejor de los casos minimizan) las 
mediaciones socioculturales que hacen posible que un individuo "se relacione" y "perciba" el ambiente. Si bien resulta lógico pensar que cada "mapa" será único e irrepetible, a la vez conviene no perder de vista las categorías, clasificaciones y modelos socialmente incorporados y puestos en acto a la hora de mirar y representar la ciudad que una investigación centrada exclusivamente en la relación (fundamentalmente perceptiva) entre individuo y ambiente pierde de vista.

Por esto debemos reintroducir lo que en términos de Lefevbre (1974) podría denominarse la dialéctica entre las "representaciones del espacio" producidas por arquitectos, ingenieros, urbanistas y políticos, entre otros, y los "espacios representacionales" propios de los actores que habitan y viven la ciudad, elaborados a partir de tales representaciones del espacio, pero no reductibles a éstas. Para decirlo esquemáticamente: la experiencia del espacio no puede realizarse sin categorías sociales, a la vez que las categorías que posibilitan y modulan dicha experiencia no la agotan.

Los dibujos de la ciudad aquí analizados serán abordados como representaciones socioespaciales, es decir, como imágenes y conocimientos sobre el espacio elaborados socialmente en función del sistema cultural y normativo, que ayudan a los individuos a comprender y a dominar su ambiente (de Alba, 2004). La noción de "representación social" presenta un uso extendido en las ciencias sociales. Su extenso uso contrasta, sin embargo, con la 
escasa precisión analítica con la que en diversos casos se aplica. La excepción a esta generalizada indefinición la constituye una corriente dentro de la psicología social que remite a las investigaciones de Moscovici (1979) y Jodelet (1991). Desde este abordaje la representación social es siempre representación de alguna cosa (el objeto) y de alguien (el sujeto), sujeto que relaciona al objeto con un contenido.

Nos alejamos de esta perspectiva en dos aspectos epistemológicos fundamentales. Por un lado, porque supone la preexistencia del objeto y, por lo tanto, la adecuación o no de la representación al mismo. Por otro lado, porque naturaliza la distinción entre un conocimiento de sentido común -susceptible de ser analizado por medio de la teoría de las representaciones- y otros modos de conocimiento, como la ciencia, sujeto a otro régimen. Para nosotros, en cambio, las prácticas discursivas son constitutivas del objeto al cual se refieren y todo tipo conocimiento es susceptible de ser tratado como formas específicas de representación social. Retomando a Daniel Mato podemos decir que mientras que en esta tradición teórica "la idea de representación social se aparea con la de realidad, es decir, se supone que la representación lo es de una cierta realidad", en el uso aquí dado "la idea de representación se aparea con la deexperiencia", lo que supone que no hay una realidad que representar sino diversas maneras de interpretar y simbolizar la experiencia social (2001: 136). 
La representación es, entonces, un proceso constitutivo (el sentido de un proceso constante de representación/interpretación de la realidad practicada) de la experiencia urbana $y$, por lo tanto, las representaciones visuales de una ciudad constituyen una vía de indagación de dicha experiencia. Las diferencias en la representación no serán ponderadas en relación a su mayor o menor adecuación a "la realidad", sino que nos hablarán de experiencias urbanas disímiles. En este sentido que trabajaremos en este artículo con los dibujos de la ciudad, entendiendo que las representaciones que se producen de la ciudad dependen de la experiencia social de los actores a la vez que organizan dicha experiencia, orientando y otorgando sentido a las prácticas, y siendo eventualmente modificadas a través de tales prácticas. La representación de la ciudad como un proceso, necesariamente inacabado, donde interactúan categorías, sentidos y prácticas de la vida urbana.

\section{Los vacíos de Garnier}

Existe un trabajo previo sobre la imagen de la ciudad de La Plata. En la década de 1980 el urbanista suizo Alain Garnier (1992a; 1992b) realizó una completa investigación sobre la historia urbana de la ciudad, que incluyó el trabajo con las "cartas

mentales" ${ }^{[2]}$ de 26 residentes de la ciudad, para lo cual retomó los postulados de Kevin Lynch. Este último estudió en tres 
ciudades norteamericanas la imagen mental que de ellas se hacían sus habitantes, concentrándose especialmente en una cualidad visual específica: la legibilidad, es decir, la facilidad con que las partes de una ciudad pueden ser reconocidas y organizadas en un modelo coherente. Aunque reconocía la existencia de "artificios simbólicos" externos que podían intervenir en su elaboración, Lynch sostuvo que las imágenes eran el resultado de un proceso bilateral entre el observador y su ambiente, donde el observador selecciona, organiza y confiere significado a aquello que ve. Sin embargo, la preocupación de Lynch como urbanista era trabajar más con las cualidades del espacio construido que con las operaciones llevadas a cabo por el observador. Usando sus propias palabras, trataba al ambiente físico como variable independiente y a la imaginabilidad como la característica (forma, color o disposición) que le confiere a un objeto físico una alta probabilidad de evocar una imagen fuerte en cualquier observador dado, facilitando la creación de imágenes mentales claramente identificadas, poderosamente estructuradas y extremadamente útiles del ambiente.

1 diseño fundacional de la ciudad de La Plata, con su énfasis en distinguir usos, jerarquizar funciones, atribuir ubicaciones, delinear circuitos, establecer ejes, en suma, con su objetivo de traducir un tipo deseado de sociedad en una forma espacial específica, pretendidamente racional, y diseñada de tal modo que sus habitantes puedan (al menos en teoría) identificar tales 
jerarquías y usos espacializados, constituye un campo fructífero donde analizar el modo en que las personas elaboran "imágenes mentales" de la misma a partir de los vínculos que establecen con ella. [3]

Siguiendo estos presupuestos Garnier muestra cómo "la geometría perfecta de la organización de los espacios urbanos" presente en el plano fundacional de La Plata no pudo resistir a los procesos urbanos del siglo XX (suburbanización, crecimiento en altura, dependencia de Buenos Aires), encontrándonos actualmente ante "una ciudad desfigurada", lo que afecta "tanto a la vida socioeconómica y cultural de sus habitantes como a los diferentes componentes de la imagen de la ciudad"(1992a: 102).

La finalidad de su trabajo con las "cartas mentales" fue establecer la diferencia existente en el caso de La Plata entre legibilidad y visibilidad. El dilema central para él era que "el plano fundacional de 1882 era perfectamente legible, la pregunta es si era visible en la realidad. Se quería averiguar cuál es la percepción que los platenses tienen de su ciudad y de su organización, qué representación pueden hacer" (1992b: 20). Para esto, identificó los componentes morfológicos y funcionales principales del plano funcional e indagó en qué medida éstos aparecían en las imágenes de los residentes entrevistados. Es decir, su modo de trabajo consistió en contrastar un conjunto definido a priori de elementos presentes en el plano fundacional (según su terminología, lo legible) con los dibujos realizados por las personas entrevistadas 
(lo visible). Su conclusión fue tajante: "el plano fundacional de La Plata contiene una estructura simbólica muy marcada, pero ese sentido simbólico fue apropiado sólo en una forma muy parcial por los habitantes (...) Se observa un desfasaje entre lo simbólico proyectado y la realidad percibida" (1992b: 21) y esto se debe, en menor medida, a cuestiones de diseño (como el elevado número de diagonales secundarias) $\mathrm{y}$, fundamentalmente, a procesos urbanos que "desfiguraron la ciudad", reduciendo así su visibilidad. Desaparición de límites y del eje monumental, conflictivas diagonales, sistema viario perturbado, sistema desfigurado de plaza, en fin, como el título de su libro lo indica, un cuadrado roto.

Precisamente por esto hablamos de los vacíos de Garnier. En lugar de indagar acerca de qué hacen las distintas personas con la ciudad, pondera en qué medida sus dibujos se adecuan al plano de la ciudad. Y es así que no encuentra más que ausencias, carencias y desvíos en los dibujos respecto del plano.

\section{Los dibujos de la ciudad:}

En total se obtuvieron 86 dibujos de la ciudad, teniendo presente la representación de las dimensiones lugar de residencia (centro/periferia) y procedencia (platense/no platense). De ellos, la mayoría (74) corresponde a representaciones visuales de la ciudad realizadas en "lenguaje cartográfico" y solo doce 
entrevistados realizaron dibujos de la ciudad que podrían clasificarse como "figurativos".

De los dibujos en lenguaje cartográfico la mayoría de ellos (66 sobre 74) fueron realizados aplicando el método global o panorámico, es decir, cada entrevistado trazó en primer lugar un marco general de la ciudad, rellenándolo luego con sus elementos principales y prestando atención a proporciones, posiciones $\mathrm{y}$ distancias entre los distintos elementos. Ese marco general inicialmente dibujado fue de dos tipos básicos. Por un lado, aquellos dibujos (41 sobre 66) en los que el entrevistado comenzó por señalar los límites de la ciudad, representados por la avenida de circunvalación, para luego representar en el mayor número de casos la plaza Moreno y las dos diagonales principales $\mathrm{y}$, en menor medida, otras diagonales $\mathrm{y}$ avenidas, otras plazas, otros hitos, etc. Se trata de dibujos que replican la imagen de la ciudad como un cuadrado que coincide con los límites del plano fundacional y donde solo en algunas excepciones (6 de 41) aparece dibujada la periferia urbana. Por otro lado, aquellos dibujos (18 sobre 66) en los que se comenzó por dibujar el centro geográfico del trazado fundacional, la plaza Moreno, y las dos diagonales principales que cruzan íntegramente el trazado fundacional, para luego representar en algunos casos otros elementos como plazas, diagonales, avenidas y grilla urbana. En los dibujos de este segundo tipo, la circunvalación de la ciudad no fue trazada y sin embargo, más 
allá de esta ausencia, la sensación que produce mirar estos mapas es, al igual que en los primeros, que la ciudad es un cuadrado. En ninguno de estos dibujos, además, fue representada parte de la periferia de la ciudad. Los límites son invisibles, pero no se dibuja nada que esté más allá de ellos.

El grado de detalle y la cantidad de elementos dispuestos en ambos tipos de dibujos varía desde representaciones sumamente simplificadas de la ciudad, como el dibujo de un cuadrado o de un cuadrado cruzado por dos diagonales hasta representaciones sumamente detalladas de diversos elementos de la ciudad. Sin embargo, independientemente de la complejidad y el grado de detalle variable, estos dibujos señalan la persistencia de la forma, la ciudad como un cuadrado y la periferia invisibilizada.

También con un "lenguaje cartográfico" fueron realizados otros dibujos (9 de 74) en los que se aplicó el método itinerante, es decir, los entrevistados dibujaron su trayecto habitual por la ciudad, el recorrido que realizan entre un punto y otro de la ciudad. De este modo Evangelina, una joven de 18 años que cuando la entrevisté hacía menos de dos meses que había comenzado a estudiar en la universidad y viajaba de lunes a viernes en tren desde Berazategui, en el sur del conurbano bonaerense, a La Plata, ante mi solicitud de que dibuje la ciudad representó el trayecto entre la estación de trenes y la facultad y mientras lo hacía sostuvo: "mucho tampoco me ubico, esto es lo que recorro, más que nada". Por su parte Daniel, un hombre de 
unos 50 años, que desde hace más de una década vive en el barrio periférico de Puente de Fierro, proveniente de Jujuy, dibujó el recorrido que generalmente realiza en moto desde su casa hasta el centro geográfico del trazado fundacional, la plaza Moreno, y mientras dibujaba me relató el trayecto, señalando los hitos más relevantes para su recorrido: "la visión que tengo de la ciudad es el único camino que recorrí desde siempre y me queda en la memoria, por supuesto que es de acá, saliendo de Puente, que yo siempre lo hago así, que es tomar por 31, tomar la rotonda, llegar a la diagonal 74 y por la diagonal pasar varias plazas, no sé cuantas, hasta la Plaza Moreno".

Así, en este tipo de dibujos está generalmente ausente una mirada panorámica y global de la ciudad. Lo que se dibuja es un trayecto. En ambos casos se plasman trayectos entre dos puntos -la estación del ferrocarril y la facultad en el primero, un barrio periférico y el centro geográfico e histórico de la ciudad en el segundo- y mientras se realiza el recorrido en el papel se señalan las referencias utilizadas para orientarse en el espacio como cruces de calles, diagonales, plazas o vías que actúan como acontecimientos en un recorrido, puntos relevantes para la orientación cotidiana $^{[4]}$.

Mientras los dibujos panorámicos suponen una lectura sincrónica de la ciudad, los dibujos itinerantes corresponden a una lectura diacrónica o secuencial de la ciudad. Por supuesto, estos tipos no son fijos y muchos de los dibujos realizados 
resultan de una combinación en proporciones variables de ambos métodos, lo que habitualmente significa dibujar un trayecto teniendo previamente una visión global de la ciudad (un marco de referencia) y no a la inversa.

\section{El mapa y sus efectos}

Como señalamos, en la mayor parte de las investigaciones consultadas se vinculan de modo más o menos lineal los mapas mentales o cognitivos con su sentido práctico: la idea de que son producto exclusivo de la práctica del espacio y, a la vez, que tienen una finalidad orientativa, eminentemente instrumental.

Por otro lado existe, sin embargo, un conjunto de investigaciones

que han enfatizado en la dimensión de poder presente en la práctica de la cartografía. Representación del espacio socialmente situada y producida que, en la medida que se vuelve exitosa, pasa por ser tratada como el espacio mismo, olvidando así su carácter ficticio, y naturalizando un modo de representación del mundo y de relación con él. En su tarea deconstructiva la geografía crítica ha sostenido que lejos de ser una reproducción fiel de lo real, los mapas constituyen una representación, lo que permite tratarlos "más como un texto que como una imagen fiel de lo real" (Montoya Arango, 2007: 167; las cursivas son mías).

Este tipo de representación moderna se basa en la "separación que los geógrafos europeos realizaron entre el centro étnico y el 
centro geométrico de observación" (Mignolo, 1995: 233). En casi todos los mapas conocidos hasta el siglo XVI, como los mapas griegos, romanos y medievales, "el centro étnico y el centro geométrico coincidían" (Castro-Gómez, 2005: 61), lo que se traducía en un tipo de representación que colocaba en el centro y con el mayor tamaño el lugar de origen del mapa, reduciéndose progresivamente el tamaño y relegándose a los márgenes del mapa los lugares menos conocidos y alejados, hasta la invisibilidad. En cambio, "la perspectiva supone la adopción de un punto de vista fijo y único, es decir, la adopción de una mirada soberana que se encuentra fuera de la representación. Con otras palabras, la perspectiva es un instrumento a través del cual se ve, pero que, a su vez, no puede ser visto; la perspectiva, en suma, otorga la posibilidad de tener un punto de vista sobre el cual no es posible adoptar ningún punto de vista (...) Al tornarse invisible el lugar de observación, el centro geométrico no coincide más con el centro étnico (...) La representación verdaderamente científica y "objetiva" es aquella que puede abstraerse de su lugar de observación y generar una "mirada universal" sobre el espacio" (Castro-Gómez, 2005: 62).

Esta ausencia de punto de vista, premisa por antonomasia de una objetividad fundada en la separación entre el sujeto cognoscente y el objeto conocido, sería el principio fundacional del pensamiento científico occidental. Es a partir de estas características que varios autores sugieren que "el mapa no sólo representa el territorio, lo 
produce" cumpliendo "no solo la función de familiarizar al sujeto con su entorno sino también aquella más profunda de "naturalizar" el orden de relaciones que le son permitidas con el espacio" (Montoya Arango, 2007: 167).

Desde nuestra perspectiva es sumamente importante reconocer que la experiencia del espacio no se agota en representaciones cartográficas como un mapa o un plano, a la vez que también es necesario señalar que los actores aprehenden el espacio a partir de un conjunto de categorías socialmente relevantes y que si la cartografía está entre esas categorías de comprensión de la realidad (vale recordar que solicitamos dibujos y realizaron mapas) debemos analizar a qué tipo de fenómeno refiere este uso. Simultáneamente, debemos evitar la tentación de encontrar "por debajo", "más allá" o "por fuera" de los mapas una lógica otra, autónoma y diametralmente distinta. El trabajo con los dibujos de la ciudad nos indica, en cambio, la emergencia de la creatividad, la singularidad e incluso el disenso a partir (y dentro) de marcos de constricción. Por esto, la concepción de Montoya Arango nos parece más adecuada cuando señala que "como en el caso de la cartografía convencional, el mapa cognitivo estará inserto en intricadas tramas de sentido, en juegos de poder que pugnan y sobredeterminan sus contenidos y sus parámetros de estructuración", debido a lo cual "el mapa cognitivo se construye en una tensión dinámica entre el imperativo espacial derivado de 
la existencia física del individuo y su posición al interior del colectivo social en que vive"(2007: 170).

En esta dirección, es indudable que la imagen dominante de la ciudad como un cuadrado remite simultáneamente a una clave de lectura de la ciudad que, a la vez que resulta útil para orientarse en la ciudad (o precisamente porque resulta útil), nos habla de una conjunto de relaciones sociales y espaciales naturalizadas, lo que se expresa en el predominio del centro sobre la periferia en los "contenidos" de los dibujos, en la generalizada invisibilización de esta última y, en los casos en que está dibujada o referida, en su definición a partir de su relación con el centro y en su relativa inorganicidad. A la vez, en algunos dibujos, como veremos, es a partir de la cartografía dominante (o en sus intersticios), que emergen otras lógicas, otras territorialidades.

\section{El cuadrado como marco}

La "educación urbana" en la ciudad supone internalizar un cuadrado. Éste es una imagen pública de la ciudad, compartida por diferentes y desiguales habitantes, que posibilita leer $\mathrm{y}$ orientarse en la ciudad. Al respecto, es relevante señalar que los elementos concretos que cada persona identifica como los límites de ese cuadrado suelen variar, aunque no aleatoriamente. Pero lo significativo más allá de estas variaciones es la imagen compartida de un cuadrado en personas que tienen una 
experiencia diferencial de la ciudad; moverse en la ciudad y conocerla supone la incorporación de un modo de representarla, un sistema de categorías, que permite luego mirarla y ubicarse. Se trata de un modelo que cada persona actualiza a medida que conoce la ciudad y que puede, incluso, llegar a cuestionar.

Un caso prototípico son los "recién llegados" a la ciudad. Incluso habiendo conocido muy poco de la ciudad, muchos de ellos dibujan un cuadrado. Violeta tiene 22 años y es de Avellaneda. Estudia en la Universidad y luego de tres largos años viajando diariamente en el ferrocarril para cursar en La Plata alquiló junto a otras amigas un departamento en la ciudad, cerca de la avenida de circunvalación. Cuando le pido que me dibuje la ciudad hace un cuadrado cruzado por dos diagonales. Y dice: "el típico cuadrito, las plazas, las diagonales, las plantitas a cada rato". Luego dibuja un círculo concéntrico, exterior al cuadrado, y remarca, irónica: "y esto no sé, no es La Plata, ¿no? La Plata no asume como tal ciertos barrios aledaños, la periferia es muy poco visible". Paradojalmente, a la vez que identifica esta característica, reconoce que ella luego de cuatro años tampoco conoce la periferia de la ciudad. Del mismo modo Fabricio, un joven de 20 años proveniente del sur del país que cuando lo entrevisté llevaba más de dos años viviendo en la ciudad, señala que "la ciudad de La Plata es así, el casco urbano y después bueno, el sector digamos marginado, igual yo no conozco todo" y agrega que "mucha gente de La Plata no sabe lo que hay 
alrededor, mucha gente estará encerrada en este casco y no se pone a pensar en los de afuera". Y el contraste entre adentro y afuera desde su punto de vista se manifiesta "en todo", es decir, "la clase que lo compone, los tipos de vivienda, el tipo de barrio, todo, es una ciudad y alrededor es otra área que no parece que fuera parte de la ciudad".

En ambos relatos la incorporación del cuadrado es anterior a la experiencia cotidiana de habitar y vivir la ciudad. Se trata de una categoría socialmente dominante y disponible que los recién llegados (fundamentalmente aquellos que ingresan a la universidad) adoptan y luego van "llenando", a medida que conocen la ciudad. Lo significativo de ambos relatos es que, incluso remarcando que la ciudad no termina donde los mapas señalan, ellos nos conocen la periferia. Es decir, saben de su existencia pero no pueden dibujarla. Sus territorialidades cotidianas no implican, en ningún caso, "salir" de la ciudad.

Así, para la mayoría de los habitantes de la ciudad el cuadrado constituye un parámetro cognitivo básico a partir del cual organizar sus territorialidades cotidianas que están en la base de su experiencia de la ciudad: qué lugares recorren, por cuáles transitan, con quiénes interactúan y qué espacios pueden representar. Por esto, incluso reconociendo que la experiencia espacial cotidiana es irreductible a la cartografía y que las representaciones espaciales prácticas son de una naturaleza distinta a la de la geometría, no podemos perder de vista 
categorías sociales como los mapas y sus efectos en la experiencia espacial cotidiana.

Reconociendo esta influencia Piccolloto ha señalado que "los mapas trazan una realidad nueva, abstracta y simbólica, según convenciones sociales validadas por el uso, que hacen que en una cierta época y sociedad se reconozca el mundo en el cual se vive en una determinada configuración gráfica" (2004: 195). Y al respecto Montoya Arango sostuvo que "esta configuración gráfica será entonces la que determine el sentido de lo real, haciendo que el mapa se superponga al territorio y anule la posibilidad de observación” (2007: 167). Quizás de manera más matizada, a partir de los resultados obtenidos, podemos decir que los mapas más que determinar un sentido de lo real y anular la posibilidad de observación, parecen en la mayor parte de las personas entrevistadas estructurar y orientar la observación, posibilitando algunas (e imposibilitando otras) miradas y prácticas.

Así, cuando vemos que luego de dibujar el plano muchos de los entrevistados traducen sus recorridos habituales en el mapa, señalan espacios e hitos significativos para su propia biografía, emiten sentimientos que le produce la ciudad o un aspecto de ella, e incluso mantienen una distancia irónica con el dibujo que acaban de realizar, nos damos cuenta que antes que agotarse en la lógica cartográfica y en el espacio geométrico, los mapas cognitivos posibilitan reconocer y reflexionar sobre el espacio 
como una tensión entre las múltiples territorialidades (Montoya Arango, 2007) involucradas en la experiencia urbana.

Michel de Certeau señaló que "entre el siglo XV y el XVII el mapa se vuelve autónomo" (2000: 133), liberándose progresivamente de los recorridos e itinerarios que eran de hecho su condición de posibilidad, consolidándose la imagen de un espacio abstracto, cuantificable, medible, objetivo. En muchas de las imágenes de la ciudad vemos reaparecer al sujeto y a las prácticas en el mapa, espacio geométrico del cual fueron progresivamente expulsadas.

\section{El punto de vista periférico}

Nos centraremos ahora en las imágenes que sobre la ciudad construyen quienes viven en espacios habitualmente invisibilizados en la mayoría de las representaciones de la ciudad. Nos interesa el punto de vista periférico sobre la ciudad. Sabemos que en la periferia coexiste una multiplicidad de puntos de vista, de experiencias y trayectorias socioespaciales. A la vez todos comparten una posición espacial y social desventajosa, más no idéntica ni tramitada del mismo modo por sus residentes. Así, pues, la pregunta que surge es: ¿cómo miran, viven y sienten la ciudad quienes habitan un espacio situado fuera de lo que habitualmente se (re) conoce como "la" ciudad? 
No hay, dijimos, un modo único de representar la ciudad desde la periferia; es más, existe una alta diversidad de tipos de dibujos con un punto en común: en todos los dibujos aparece el propio lugar de residencia y se menciona la relación de éste con "la ciudad". Es decir, se asume algún tipo de diferencia entre la periferia y la ciudad y, a la vez, se enuncia el tipo de relación que se establece entre ambos espacios: distancia, ajenidad y/o separación.

Así, cuando le propongo a Azucena, una joven ama de casa de 21 años procedente de Tucumán que vive desde hace unos años en Puente de Fierro con su marido y sus dos hijos, que dibuje la ciudad, me contesta “ ¿la ciudad o acá, el barrio?” y me cuenta que en la ciudad "las diagonales me pierden, hay muchas diagonales. Después me ubico con las calles, pero cuando hay diagonales...Si yo me voy sola, me pierdo y no vuelvo más. Te hago el barrio, mejor" y agrega "porque yo, desde que estuve acá no fui de salir".

Tanto en lo extremadamente acotado del espacio representado como en la ajenidad manifestada en relación con la ciudad (visitas esporádicas, desconocimiento, confusión) la representación de Azucena contrasta con otras representaciones de la ciudad desde la periferia como la imagen panorámica de la ciudad realizada por Carlos (dibujo 1) y también con otras representaciones realizadas por vecinos de Azucena. Así, Joaquín, referente de un comedor barrial, compone la siguiente imagen de la ciudad. 


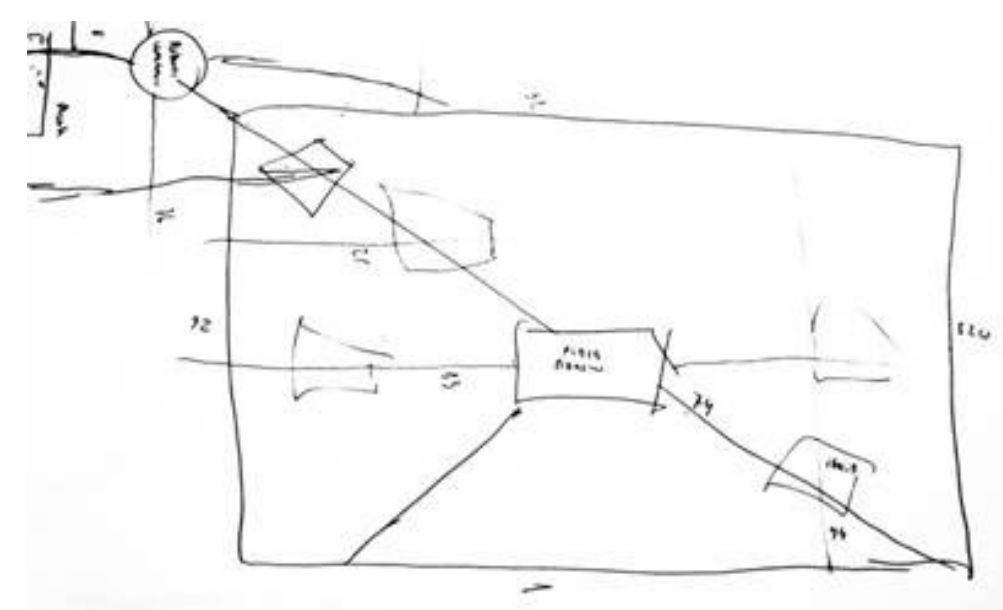

Y señala: "la ciudad de La Plata es la ciudad de las diagonales. Puede hacerse un cuadrado [dibuja el cuadrado] Después tenés diagonales, yo de las diagonales no me acuerdo muy bien, pero sí, hay una diagonal que pasa, supuestamente, esta es donde estamos nosotros no es cierto? [señala diagonal 74, que va del extremo superior izquierdo de su cuadrado a la plaza Moreno, ubicada en el centro del dibujo]. Llegás desde acá [el barrio] al centro, Plaza Moreno...bueno, que vas hasta 1 [extremo inferior derecho de su cuadrado]. Después tenés, acá tenés la 25 , por acá pasa por 13, de acá sale otra diagonal que es diagonal 80 , esta es $1,32,72,520$ [señala los límites del cuadrado] Esta es diagonal 74, después venís, hacés un poquito más está la rotonda del cementerio [extremo superior izquierdo del dibujo], agarrás 31 , acá ya agarrás 31, hacés para acá, entonces Puente estaría más por acá [dibuja su barrio]".

A partir de su dibujo (y del relato que lo acompaña) Joaquín compone un escenario de desplazamientos sumamente 
instructivo, donde se combinan una imagen visual panorámica compartida por vastos contingentes de los habitantes de la ciudad con la posición que él y su barrio ocupan con respecto a dicha imagen y el itinerario que debe realizar para conectar ambos puntos. Está claro que para él, al igual que para Azucena, la ciudad (cuadrado, diagonales) y el barrio no se confunden ni son lo mismo; la diferencia con Azucena radica en el tipo de relación que ambos establecen con la ciudad. De la experiencia de Joaquín se puede inferir que la ciudad está lejos, más no que es algo totalmente ajeno a su cotidianeidad.

A la misma conclusión se puede arribar al observar el dibujo de la ciudad (y leer el relato) de Ester, una mujer de 35 años procedente de Villazón (Bolivia), que hace más de diez vive en el barrio. Estamos en el comedor que ella gestiona desde hace años, charlando y tomando mate; está anocheciendo. Desde hace un rato está junto a nosotros la suegra de Ester, doña Clara, oriunda de La Paz, lugar al que no ha vuelto desde cuando emigró hacia Argentina, hace 40 años, primero a La Quiaca (donde nacieron sus hijos, uno de ellos Javier, el marido de Ester), luego a Córdoba y ahora La Plata. Ante mi solicitud, Ester comienza a dibujar su ciudad; el dibujo terminado es el siguiente. 


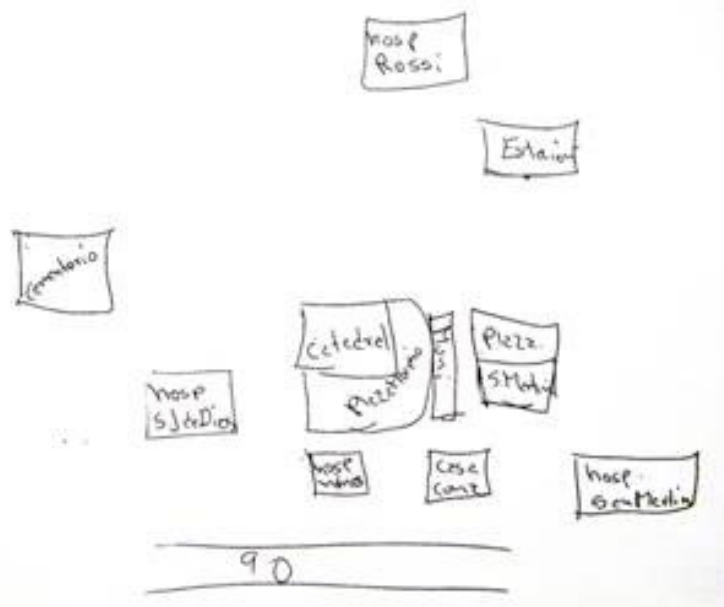

Y mientras dibuja, charlamos:

E: Primero la 90 [calle en la que se encuentran su casa y el comedor; más allá de la 90 hay descampado]. Esta es la 90, donde estamos nosotros, bueno por acá está el hospital San Juan de Dios. Después, y más por acá está la catedral. Y después la Plaza San Martín que está por acá.

$\mathrm{R}: \mathrm{Si}$

E: y más por acá la Estación de trenes, que es histórica también, para nosotros, ese era nuestro punto de concentración para ir a los piquetes

R: Ahí se encontraban, ustedes iban de acá del barrio hasta la estación

E: Hasta la Estación, con nuestra plata, como podíamos, nosotros por ejemplo había un tiempo que todos los varones de acá iban en bicicleta. Y después acá, Plaza San Martín, Catedral, que estaría ahí la Plaza Moreno no? 
R: Claro

E: Y acá sería la municipalidad

Doña Clara: Las Torres también Ester

E: Las torres?

Doña Clara: Claro, hay 1 y 2 [se refiere a dos torres adyacentes de la municipalidad donde funcionan dependencias del gobierno provincial]

E: Pero eso no! Doña Clara

(risas)

E: Y por este lado, de la 90 por acá, más o menos, sería el San Martín. Y sería por acá de la Estación, por acá atrás sería el Hospital Rossi, ahí me operaron a mí. Esos serían los puntos más importantes para mí.

Doña Clara: Cementerio no has puesto

E: No!, el cementerio no me gusta (Risas)

R: Claro, ese lugar mejor no ir no?

E: El cementerio está por acá más o menos

Doña Clara: Cementerio, cementerio, vamos a llegar algún día igual, todos.

E: Yo no me quiero quedar acá, me voy a mis pagos que me lleve. Eso le diría a mi hija yo. 
Está claro, el dibujo de Ester sintetiza parte de su experiencia de la ciudad: el lugar desde donde mira la ciudad ("la90"), ciertos hitos urbanos compartidos como la Catedral y la Municipalidad, los distintos lugares por donde circula o ha circulado en el pasado (el hospital donde la operaron, la municipalidad donde gestiona recursos, la estación del ferrocarril hacia donde se dirigía para ir al piquete), las distancias a cubrir y las carencias de recursos monetarios para hacerlo e incluso cierto sentimiento de extranjería y el deseo de morir en su tierra. Se trata, además, de un dibujo sumamente original e infrecuente entre los obtenidos en el trabajo de campo, por dos motivos. En primer lugar, reaparece el punto de vista que la cartografía expulsó. Ester dibuja la ciudad como ella la ve desde su lugar de residencia. No realiza un cuadrado y luego ubica su barrio en relación al mismo, aceptando la perspectiva geométrica y totalizadora, sino que dibuja en primer lugar su posición y desde ahí, mira la ciudad y la representa "como se ve" desde el punto desde el cual ella la mira. En segundo lugar, mientras en la mayoría de las investigaciones se resalta que, en general, las sendas o vías son utilizadas para conferir una estructura a la imagen de la ciudad (y nuestro caso no ha sido la excepción en este sentido) en el dibujo de Ester se señalan hitos urbanos (plazas, hospitales, estación de ferrocarril, catedral, cementerio) distribuidos en el espacio según su posición 
y distancia relativa entre sí y con el punto de observación de Ester, sin que ninguna vía o senda los conecte.

A partir de las diferencias entre los dibujos de Azucena, por un lado, y de Joaquín y Ester, por otro, se puede sostener que en el tipo de dibujo intervienen múltiples factores como la procedencia, el tiempo de residencia y el tipo de actividad que se realiza, los cuales influyen tanto en el conocimiento de la ciudad como en las territorialidades cotidianas de cada una de las personas. De todos modos, más allá de las diferencias entre los dibujos, el punto de vista periférico llama la atención sobre las debilidades de una teoría de la adecuación de las representaciones sociales. En lugar de interpretar esos dibujos por sus inadecuaciones, desvíos y carencias con respecto al plano, nos hablan de formas de vincularse con la ciudad, de modos diferentes de vivirla. En efecto, si dirigimos nuestra mirada y nuestro cuerpo hacia la periferia para conocer otras vidas, con lo que nos encontramos es con otras ciudades, las cuales remiten a experiencias, trayectorias y territorialidades distintas. Nos desplazamos de la inadecuación entre dibujos y ciudad a los modos -diferentes y desiguales- de estar y de hacer en la ciudad, de experimentar un lugar: "fabricaciones de espacio", como bellamente las denominó de Certeau (2000: 134)

Epílogo. Vivir afuera, las significaciones de las imágenes de la ciudad 
Las cuestiones formales y cognitivas han sido las más trabajadas en las investigaciones sobre imágenes de la ciudad. Sin embargo, al ver los dibujos y los relatos que generalmente los acompañan es imposible no hacerse la pregunta por su significado. En este sentido Charles W. Morris formuló el concepto de territorialización emocional con el cual señaló que el habitante busca configurar o traducir territorialmente aquellas percepciones y sentimientos experimentados y vividos dentro del espacio urbano marcando los lugares significativos. Según Agusti (2005) se trata de una dimensión complementaria a las indagaciones de Lynch: para orientarse el individuo es capaz de establecer tanto centros, direcciones, ejes, llenos y vacíos como presencias, vivencias, recuerdos y olores. Incluso muchas veces los mapas mentales pueden estructurarse más a partir de instantes, de sensaciones y de encuentros, de espacios llenos y vacíos, que de instituciones, hitos o monumentos. Así, en muchos de los dibujos obtenidos se señalaban simultáneamente una configuración espacial determinada (y muchas veces compartida con otros) y un conjunto de significados y sentidos singulares (incluso biográficos) ligados a lugares específicos: la dirección en la que se encuentra el lugar de procedencia, la ubicación de la casa propia, el lugar de nacimiento de un hijo, el hospital donde la persona fue operada, entre otros.

Más allá de estos lugares significativos, que nos revelan las múltiples fuentes de las que se nutren los dibujos y, una vez más, 
nos dan pistas acerca de que los dibujos nos hablan de formas de experimentar la ciudad por parte de sus habitantes, nos interesa detenernos especialmente en una conjunto de sentimientos que se expresan en los dibujos de la ciudad realizados por habitantes de la periferia, los cuales no se limitan a hitos particulares, sino que hablan de la experiencia del vivir afuera.

Introducimos un último dibujo. En este caso su autora es Aurora, una mujer de 58 años que reside en un asentamiento de las afueras de la ciudad desde hace tres años, cuando llegó con sus hijos, hijas y nietos procedentes de Misiones. Es un de los pocos dibujos "figurativos" que se obtuvieron sobre la ciudad. Aurora no recurrió al mapa ni a la ayuda del lenguaje cartográfico (¿es probable que esto exprese su procedencia, su escaso tiempo de residencia y una vida centrada en su barrio?) sino que dibuja en tres dimensiones el barrio, la ciudad, las casas y las calles. Y más relevante que lo que dibuja y cómo lo hace, es lo que busca transmitir con su dibujo: un sentimiento acerca de lo que es vivir en ese barrio y la relación que tiene con el resto de la ciudad. 


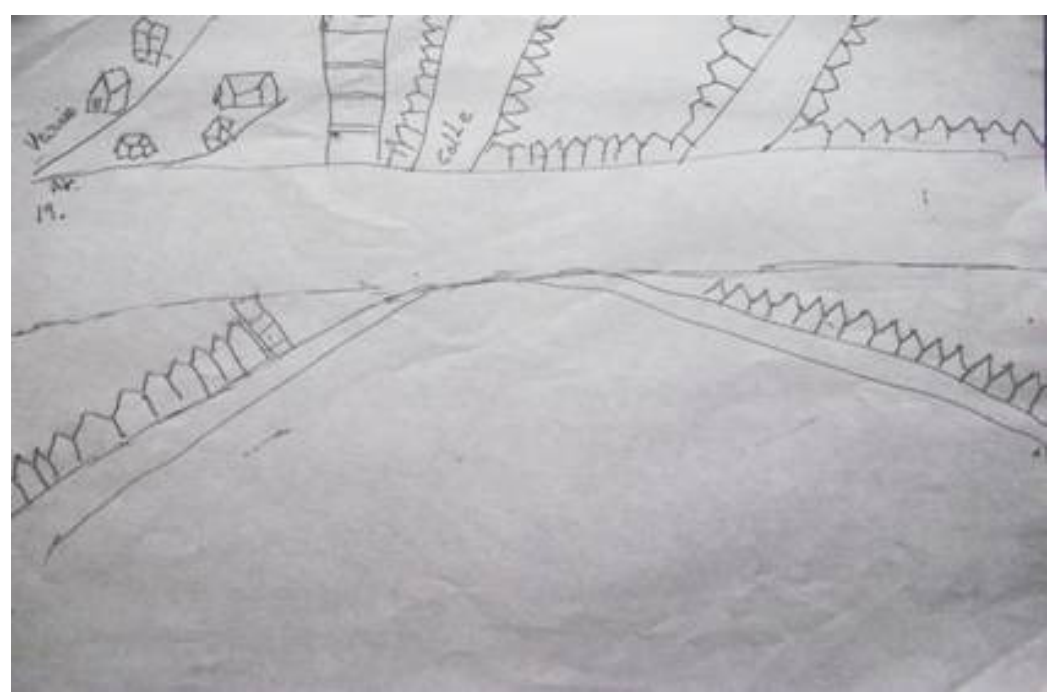

A medida que lo dibuja charlamos:

A: Esta es la calle, esta es la ciudad, todo así [realiza hileras uniformes de polígonos], este es un barrio [extremo superior izquierdo del dibujo; dibuja casas dispersas]

$\mathrm{R}:$ ¿A ver cómo es?

A: Las casitas, estas son las casitas [señala los polígonos uniformes], y acá, esto es un barrio ¿viste? este es un barrio [extremo superior izquierdo del dibujo] y esto la ciudad

R: ¿Y esto qué, es una calle esta ancha?

A: Claro, una avenida, la 19

R: Aurora una pregunta, ¿qué quisiste marcar en esta diferencia entre este tipo de construcción y acá, la del barrio?

A: Y qué está dividido

R: Están divididos?

A: Sí, el centro es una cosa y el barrio es otra 
Barrio y ciudad están divididos. Con su dibujo Aurora está intentando expresar un sentimiento fuerte acerca de cómo es vivir en el lugar donde vive. Sentimientos de ese tipo -aunque no necesariamente los mismos- emergen en todos los dibujos realizados con habitantes de la periferia. Recordemos $l a$ ajenidad con la ciudad manifestada por Azucena cuando señalaba la confusión que le produce ir al centro y el temor a perderse; las carencias señaladas por Carlos al marcar el contraste entre el cuadro (todo entre "cuatro fierros") y su barrio ("no hicieron nada, no hay edificios, colegios, hospitales"); la distancia remarcada por Joaquín al describir el largo trayecto entre su barrio y el centro.

División, ajenidad, carencias, distancias... De diferentes modos, todos estos dibujos remiten a la distinción entre ciudad y barrio (complemento necesario de la visión dominante de la ciudad como un cuadrado) y nos hablan de la relación que se mantiene con la ciudad y de los sentimientos que esto genera.

\section{Bibliografia:}

AGUSTI, Andreina (2005) "Mapas mentales y ciudad", en Fermentum (15/42).

CASTRO GÓMEZ, Santiago (2005) La poscolonialidad explicada a los niños. Popayán: Universidad del Cauca. 
CASTRO, Constancio (1999) "Los mapas cognitivos. Qué son y cómo explorarlos", en Scripta Nova (33). Accedido en Mayo de 2007.

DE ALBA, Martha (2004) "Experiencia urbana e imágenes colectivas de la ciudad de México", en Estudios Demográficos y Urbanos (21/63): 663-700.

DE CERTEAU, Michel (2000) La invención de lo cotidiano I. México: ITESO.

GARNIER, Alain (1992a). El cuadrado roto. Sueños y realidades de La Plata. La Plata:

LINTA, CIC y Municipalidad de La Plata.

GARNIER, Alain (1992b) "Los espacios públicos de La Plata: de la tradición a la modernidad". En: La Plata: de la ciudad antigua a la ciudad nueva. La Plata: LINTA, CIC y Municipalidad de La Plata.

GOULD, Peter (1966) On Mental Maps. Michigan: Michigan Inter University Community of Mathematical Geographers.

HARLEY, John (2001) The new nature of maps: essays in the history of cartography. Baltimore: The John Hopkins University Press.

HARVEY, David (1998) La condición de la posmodernidad. Buenos Aires: Amorrurtu editores.

JODELET, Denise (1991). "Representaciones sociales: un área en expansión". En: Sida: imagen y prevención. Paez, J. (Ed.). Madrid: Editorial Fundamentos. pp. 18-41.

LEFEVBRE, Henry (1974) La production de l"espace. Paris: Anthropos.

LOWENTHAL, David (1967) Environmental Perception and Behavior. University of Chicago, Research Paper $\mathrm{n}^{\circ} 10$.

LYNCH, Kevin (2006) A imagen da cidade. San Pablo: Martins Fontes.

MATO, Daniel (2001) "Producción transnacional de representaciones sociales y transformaciones sociales en tiempos 
de globalización", en: Mato, Daniel (Comp.) Cultura y transformaciones sociales en tiempos de globalización. Buenos Aires: CLACSO.

MIGNOLO, Walter (1995) The Darker Side of the Renaissance. Literacy, Territoriality and Colonization. Ann Harbor: The University of Michigan Press.

MONTOYA ARANGO, Vladimir (2007) "El mapa de lo invisible. Silencios y gramática del poder en la cartografía", en Universitas Humanística (63): 155-179.

MOSCOVICI, Serge (1979) El psicoanálisis, su imagen y su público. Buenos Aires: Huemul.

PICCOLLOTTO, Beatriz (2004) "Decifrando mapas: sobre o conceito de "território" e suas vinculacoes con la cartografía", en Anais do Museu Paulista (12/12): 193-234.

\footnotetext{
[1] Licenciado en Antropología (UNLP). Programa de Doctorado en Ciencias Sociales (UNGS-IDES). Investigador y docente de la Universidad Nacional de La Plata y del Instituto de Altos Estudios Sociales (UNSAM).
}

\footnotetext{
[2] No hemos accedido a dichas imágenes sino a publicaciones en las cuales Garnier hace alusión a su investigación sobre "cartas mentales" y enuncia algunas conclusiones derivadas de los resultados obtenidos a partir de las mismas.

${ }^{[3]}$ La Plata fue fundada el 19 de Noviembre de 1882 como nueva capital de la provincia de Buenos Aires. Una de sus características distintivas es que se trata de una ciudad planificada. El diseño original consiste en un cuadrado de 40 por 40 manzanas -5 Kilómetros por lado-, claramente delimitado por una avenida de circunvalación de 100 metros de ancho cuya función era separar el centro de la periferia, lo urbano planificado de lo rural. Al interior del cuadrado predomina la disposición en cuadrícula, con avenidas cada seis cuadras, en cuya intersección se encuentran espacios verdes (plazas y parques) equidistantes. Dos diagonales principales y otras seis secundarias procuran dar agilidad a la circulación por el cuadrado y conectan el centro de la ciudad con la periferia. Un eje monumental que corre a lo largo de las avenidas 51 y 53 divide simétricamente al cuadrado fundacional, y en él se encuentran emplazados los principales edificios públicos, distinguiendo así lo público de lo privado. Actualmente dicho cuadrado fundacional se encuentra rodeado por un cinturón periférico entre los cuales existen grandes contrastes poblacionales (200000 habitantes en el cuadrado, 400000 en la periferia), urbanísticos y socioeconómicos.
}

\footnotetext{
${ }^{[4]}$ Se podrían comparar estos trayectos dibujados por los entrevistados con el trazo de los mismos recorridos sobre la cartografía oficial. Se observarían desvíos y distorsiones. ¿Podríamos deducir falta de orientación? Por lo argumentado hasta aquí, seguramente no. Nuestros entrevistados no se pierden en la ciudad al realizar estos recorridos habituales. La distorsión (con respecto a la cartografía oficial) no puede ser interpretada mecánicamente como desorientación. Más relevante es ver en estos dibujos y relatos formas cotidianas de orientación a partir del uso de elementos (hitos, calles, indicadores) distintos al de la racionalidad matemática y abstracta propia del proyecto fundacional.
} 
